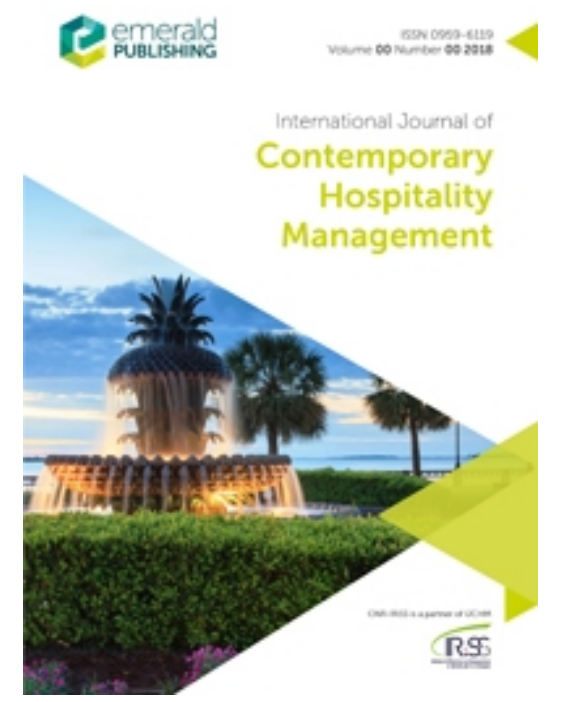

\title{
Rebounding through the Pandemic: Towards the Digitized and Digitalized Small Hospitality Business in China
}

\begin{tabular}{|r|l|}
\hline Journal: & International Journal of Contemporary Hospitality Management \\
\hline Manuscript ID & IJCHM-09-2020-0982.R3 \\
\hline Manuscript Type: & Original Article \\
\hline Keywords: & $\begin{array}{l}\text { Qualitative methods, China, Information Technology, Small businesses, } \\
\text { Case Studies }\end{array}$ \\
\hline
\end{tabular}

\section{SCHOLARONE ${ }^{m}$ Manuscripts}




\title{
Rebounding through the Pandemic: Towards the Digitized and Digitalized Small Hospitality Business in China
}

Never let a good crisis go to waste - Sir Winston Churchill

\begin{abstract}
Purpose: Grappling with the sweeping pandemic, the Small Hospitality Business (SHB), smaller in scale and weaker in risk mitigation, has been seriously affected. The research supplements the unrepresented area of SHB in China from the digital perspective by drawing on Instrumentalization Theory.
\end{abstract}

Design/methodology/approach: Based on two appropriate and detailed SHB cases, we adopted a qualitative approach to understand and conceptualize the focal issue.

Findings: The study identified the factors affecting SHB at operational, managerial, and transformational levels amid the crisis. It further developed a theoretical framework of the SHB rebound matrix, highlighting the importance of digitization and digitalization.

Implications: The research theoretically confirmed that SHB is internally, externally, and essentially restricted and developed a corresponding rebound matrix. It practically supports SHB'S transformation by making recommendations to unleash the potential of digital business.

Originality/value: Our study complements extant descriptive and atheoretical research by focusing on SHB's underlying digital nature through the lens of Instrumentalization Theory, providing an evidenced theoretical understanding of SHB's development amid and after the pandemic.

\section{Keywords}

Small Hospitality Business, China, Case Study, Qualitative Research, Pandemic, Digitization, Digitalization 


\section{Introduction}

Recognized as the "worst crisis since the Second World War" (Guterres, 2020), the ongoing pandemic caused by Covid-19 (coronavirus), has put the entire world in dire straits. In a series of concerted responses to curb the spread of Covid-19, the Chinese government has implemented policies involving border shutdown, travel restrictions, and mandatory quarantine, sparking concerns over impending economic pressure on a wide spectrum of sectors. The hospitality industry, in particular, is regarded as the most devastated sector amidst the crisis with the market experiencing unprecedented hardship: the hotel occupancy rate fell from $70 \%$ on 14 January 2020 to $7.4 \%$ and the overall prices plummeted by more than $50 \%$ during the first week of February 2020 (Hospitality and Catering News, 2020). The Small Hospitality Business (SHB) is no exception. While traditional hotels, especially those part of renowned domestic and international chains, such as the Huazhu Hotel Group, Jinjiang International, and Hilton Worldwide, are involved in heated discussions surrounding "survival and revival" throughout the pandemic (e.g., Gupta, 2020; Lai and Wong, 2020), the SHB is largely downplayed during this.

In different contexts, scholars use SHB, homestay, guesthouse, commercial home, etc., when referring to a similar concept; this study chose SHB, as the discussion regarding their differences is outside the scope of our research. Evolved from bed and breakfast (B\&B), established for decades in Western markets, China's SHB has been enabled by a wave of digital innovation-led sharing economy (SE) initiatives (Li et al., 2017), referring to privately owned and operated hospitality services of various types and styles (Lyu et al., 2019). Web 2.0 has revolutionized how people connect with others and share information online, giving rise to SE initiatives, attracting consumers by sharing and using resources with higher convenience and lower prices (Camilleri and Neuhofer, 2017). In the landscape of the hospitality sector, this has led to a shift in demand for sharing platforms in contrast to the predominant traditional ownership that witnesses the arrival of numerous SHBs, and the advent of global platforms such as Airbnb and Tujia in China, where increasing numbers of SHBs are listed.

Relatively more recent in history and significantly propelled by the frog leap in SE, SHB in China bolted into a burgeoning market from 2015 onwards (Feng and Han, 2020), swiftly making the mark in the form of more than 169,477 operation businesses across 31 provincial administrative regions of 355 cities (Guo et al., 2020). The descriptive statistics, however, suggest that SHB is more likely to be affected by the pandemic. According to the latest report released by China Hotel Association (CHA), while both traditional hotels and SHBs witnessed an approximately 70\% drop in occupancy rate, the decrease in the standard rate is significantly uneven: $11 \%$ for hotels compared to $50 \%$ for SHBs. In addition, during the outbreak of the pandemic, $27 \%$ of hotels remained in business in contrast to only $14 \%$ of SHBs (CHA, 2020). Understandably, the advantages of larger scale and capital enable hotels to better withstand potential risks, but it is equally worrying to observe that SHB is particularly and profoundly affected by the pandemic. In this regard, well-focused research in understanding how SHB is affected and how it can rebound is timely and important.

The current research regarding SHB in China is largely limited and sporadic as the extant investigations are few, generic, and piecemeal (Feng and Han, 2020). A majority of these studies concentrate on the developmental issues such as SHB's influences on the local economy (e.g., Sun et al., 2016), and SHB's improvements for customer satisfaction and targeted segmentation (e.g., Jiang and Li, 2014), which are primarily undertaken from the service perspective. It hence fails to consider SHB's underlying digital nature, which is rooted in a scenario of digital innovation, limiting the current endeavors. Furthermore, most researches are descriptive and atheoretical, as they did not look into the issue through a possible and sensible theoretical lens. This shortcoming has prevented the research 
outcomes from being applied to a wider range of occasions as SHB has not yet generated its own relevant frameworks for the development. To this end, the existing studies on SHB in China generally overlooked the digital context of SHB while overshadowing the objective of understanding SHB in a more systematic and in-depth manner. In view of the above, the research questions arise:

(1) How, and why, is SHB in China specifically affected by the pandemic?

(2) How can SHB in China meaningfully and feasibly rebound from the pandemic?

We believe this research is of high academic and practical importance. This study identified the obstacles facing SHB in China during the pandemic, and developed theoretical-framework-based measures for SHB development after the crisis. It hence provides a first-hand understanding of the reasons behind the current predicament of SHB in China and formulates a first theory-based set of factors and measures for its regeneration. The study also formulates a collection of practical references for the SHB sector and the practitioners to better leverage the digital potentials that they should be fully cognizant of.

The remainder of this paper proceeds as follows. First, the literature is examined in Section 2 to provide the topical foundation and identify the key research gaps. Following the methodology section describing the data collection and sampling procedure in Section 3, the findings are presented in Section 4. Section 5 discusses and concludes the research with the implications and limitations.

\section{Literature Review}

\subsection{Small Hospitality Business in China}

Being another renewed instance of sharing economy, SHB has garnered much attention as an emerging economic model through collaborative consumption (Williams and Horodnic, 2017). Individuals who possess spare resources, such as rooms, will share their unoccupied capacity with peers in return for a certain amount of monetized benefits on innovative channels and/or platforms (Barron et al., 2018). This newly evolving form of hospitality service has refueled the development of the B\&B and upheld its digital transformation on an unprecedented scale. Globally, the SHB market is valued at $\$ 15$ billion at the end of 2016 (Escobar, 2016), and is expected to grow 31\% annually to at least 2025 (Rein, 2017). Locally in China, a similar trajectory is witnessed and envisaged. The number of online homestay accommodations increased from 592,000 in 2016 to 1.34 million in 2019, and the transaction volume of China's shared accommodation market climbed to 20.9 billion in 2019 from 4.3 billion in 2015 (China Tourism Homestay Development Association, 2019).

Following decades of extraordinary economic growth, from the outset in 2015, SHB has undergone rapid development in China, sprawling across almost all provinces and attracting wide public awareness (Zhang and Wang, 2017). At the confluence of growth in the tourism sector and unfolding digital transformation in China, SHB presents a hotspot for increasing employment opportunities (Fang et al., 2015) and a continued influx of capital investments (Liu and Cheng, 2018). It also provides the opportunity for an increasingly large group of customers who are educated and develop the taste for a personalized hospitality service (Sigala, 2018). It has thus become another economic powerhouse (Suo, 2017), receiving strong support from the government since 2015 and wide acceptance amongst the public in China $(X u, 2020)$.

A multitude of research focuses on a wide range of developmental issues of SHB in China. The first cluster surrounds its increasing influences on economic development. Zhu (2014) affirmed the potential role of SHB in facilitating rural development, while Zhang and $\mathrm{Hu}$ (2016) cautioned that a reasonable position of SHB in the local economy scheme is a prerequisite for "healthy" development. 
As a response, Xiao et al. (2019) recommended a number of measures to adapt SHB with the local cultural and economic status to achieve "sustainable" development. Other scholars, however, are more interested in the development of SHB per se through better product design (e.g., Zhai, 2016), targeted customer orientation (e.g., Sun, 2019), and precise market segmentation (e.g., Jiang and Li, 2014). In all, they set out a promising picture of SHB itself and its impacts on society.

However, the development of SHB in China is not without pressure. Radzi et al. (2014) observed that SHB owners usually operate their business with a small-scale investment to pay back in a relatively short period, suggesting that the cash flow is not always readily sufficient. As a result, most SHBs are not resilient or resistant to potential risks, and they are more likely to suffer from cash shortages (Forgacs and Dimanche, 2016). Due to their comparatively nascent nature, SHBs in China are largely short of infrastructure facilities, share very similar characteristics and connotations (Zhang, 2019), and have a lower standard of hygiene (Shi and Huang, 2019). In other words, the SHB's rapid development is partially grounded on a simplified version of successful stories, resulting in a high degree of similarity for architectural style, interior decoration, and additional services (Luo, 2017).

Those endeavors, albeit limited, provided a number of constructive insights into the status quo of SHBs in China. They approached the SHB primarily from the developmental perspective without considering its latent essence - the digital innovation. SHB's digital nature - the core and inherent impetus enabling the establishment, while driving its evolvement - is overlooked. In addition, most studies are descriptive in nature as they do not employ a theory-related or theory-based lens to thoroughly examine the issue, resulting in atheoretical attempts and empirical-only findings. This suggests that the extant outputs cannot be readily or convincingly generalized to a larger scale, overshadowing the objective of understanding SHB in a more systematic and in-depth manner. Our study, therefore, supplements previous research by providing a complementary digital perspective through the lens of Instrumentalization Theory (IT).

\subsection{Covid-19 Impacts on SHB in China}

It is agreed that the hospitality sector is one of the worst-hit sectors amid the Covid-19 pandemic (e.g., Baum and Hai, 2020; Johns and Comfort, 2020; Knight et al., 2020) as travel restrictions have significantly affected the tourism industry. Overall, the entire sector in the first two months endured a net loss amounting to 67 billion CNY with an estimate of an annual decrease at $24 \%$, equivalent to 130 billion CNY (CHA, 2020). Despite the grave situation, traditional hotels seem to have outpaced SHBs in coping with the crisis. The hotels experienced only $11 \%$ price decrease in general, whereas SHBs underwent a much bitter scenario with a $50 \%$ decline; furthermore, the percentage of hotels remaining in operation is almost as twice as that of SHB ( $27 \%$ and $14 \%$ respectively) (CHA, 2020).

In addition, given the fact that traditional hotels are generally larger and more systematic in hygiene management than SHBs, the local governments selected dozens of traditional hotels ranging from budgeted hostels to luxurious hotels (Kamin, 2020) as the dedicated self-paying 14-day quarantine venues for flocks of inbound returnees from overseas. This move has alleviated the financial pressure facing the traditional hotel chains to the extent that the unoccupied rooms will be made most use of, whilst SHBs are entirely excluded from this measure. In sum, the SHB is not only disproportionately affected by the pandemic, but is also struggling to rebound through it.

It is worth noticing that due to the comparatively successful control of Covid-19 in China, the restrictive lockdown across the nation was phased out after April 2020 (China Government, 2020). Despite some minor regional outbreaks, which were promptly addressed by the local government, China spared no efforts in "advancing work resumption" (China Government, 2020) thereafter, and 
the hospitality sector is no exception. The favorable external environment least disrupted by Covid-19 since then has, thus, assured a relatively propitious development context for SHBs. Considering the dearth of related research surrounding SHBs in China against the pandemic, in particular the actionable measures that may bolster SHBs for after-lockdown and post-pandemic development, our research serves as a response to Jiang and Wen's call (2020) and is of great importance and timing.

\subsection{Instrumentalization Theory}

In order to address the weaknesses arising from previous studies, we examined the focal questions through IT, which proves to be useful in understanding technology's presence in social existence (2008). Departing from the well-accepted notion that technology has a number of social implications, IT successfully reconciled the argument between constructivism and substantivism, as the former focuses on the specific social factors for technology while the latter holds technology as the general enabler in the social context (Price et al., 2013). IT argues that not only is the technology socially determined in contexts, but it entails a swathe of social implications that demand general attention.

Specifically, IT posits that technology should be analyzed at two different but related dimensions - the functional dimension and the implementation dimension. The dual dimensions contemplate the perspective that technology cannot be related to social affordances without being in a specific social context. To this end, as opposed to narrowing the scope to merely what technology does, IT addresses a wider range of issues as to what technology means, and how and why at different dimensions. The functional dimension primarily involves decontextualization, in which the focal object must be understood surrounding its specific function and relevant useful properties without considering the real-life context - a general perspective. The implementation dimension, however, relates to recontextualization, which enables the act of arranging technology into the life setting by incorporating it with social, economic, and cultural values - the specific contexts. These two dimensions are analytically distinguished as they speak to distinctive affordances that are attached to the technology, but can be appreciated as a whole given that the societal goals are integrated into technological functions. In this regard, Feenberg suggests that "the implementation dimension plays an increasingly important role" as the technology advances (2008).

IT hence provides a holistic perspective by facilitating technology-focused analysis in different dimensions and can contribute meaningfully to the complicated but less-researched issues, such as SHB in China. Further, considering the unique strength inherent in IT, that technology can be analyzed at both specific and general levels within two dimensions, we are thus able to examine the digitalenabled SHB in a more structured and comprehensive manner. It has proved useful in analyzing existing technology and identifying its undiscovered potentialities (Bos, 2008) in a wide range of technology-related phenomenon in various domains, such as education (e.g., Ankiewicz, 2019; Boelt and Sorensen, 2017) and healthcare (e.g., Costa, 2020; Souza, 2016). In light of these academic benefits and practical usefulness, we utilize IT in an attempt to develop a systematic apprehension towards SHB in China that is empowered by digital innovation.

\section{Methodology}

\subsection{Rationale for qualitative interpretive case studies}

In general, an interpretive qualitative method accommodates ideally the little-studied phenomenon, such as SHB, and can ensure a rich understanding arising naturally from the interaction between researchers and key SHB practitioners for informed conceptions and enhanced understanding (Bygrave, 1989). Specifically, an interpretive research suitable for an issue with high dynamicity and 
complexity. In this scenario, researchers are supposed to consider the industrial, technical, and social aspects and their continued interaction with the utilization of digital innovation and the ongoing context (the pandemic, in this case) (Lee, 2004). When a prompt response is needed to address a developing situation, subjective data is preferred given that "objective data would have been collected at precisely the right times or instances" (Smith et al., 1989). To this end, the quantitative approach cannot reveal the 'whole story' (Crotty, 1998). Qualitative research, however, generates contextual data in abundance (Robinson, 2001) through various forms of researchers' engagements in a natural manner (Creswell, 2009). Researchers are thus able to observe the subjects and their surroundings, interact with the participants, and take notes of all available raw data, thereby developing an in-depth case from the insider's perspective rather than the onlooker's. The case-study approach speaks convincingly of 'why' and 'how' questions (Myers, 2019) and is particularly suited to exploratory studies (Babbie and Mouton, 2001) considering the fact that it fosters a research surrounding where the behaviors of subjects naturally occur (Zainal, 2007). In particular, it assists in building theory (Yin, 2009) as well as testing theory (Ridder, 2017), suggesting its usefulness of being applied to the area under study, SHB in China for instance, where the theoretical understanding is lacking (Gerring, 2004). As such, the case study approach fits the nature of our studies.

We followed a two-case study method for the following reasons. In order to examine representative SHBs while maintaining the research rigor and precision, we must pre-define the boundary to scope the analysis at hand. Regarding the nascent nature of the focal issue, the scope would be unnecessarily large if we intended to cover multiple cases, but would also be unconvincingly small if only one case was selected. Keeping to two sites of SHB enables us to engage with a reliable and replicable design of the case study (Yin, 2013), while practically fulfilling the purpose of comparison. Two case studies of different but exemplary SHBs were used to illustrate the activities being taken and envisaged amid the pandemic. To this end, the inclusion of two cases, rather than only one, is valuable.

Literature regarding SHB, including the records of the industry performance, served as an overarching background for data collection. This approach enhanced the research's construct validity leading up to the case study stage. We took a between-method triangulation of data from semi-structured interviews and various secondary documents to diversify the sources for data richness (Paul, 1996). We collected data from two high-ranking SHBs in one of the cities where SE-based SHB is actively flourishing in the Chinese market; both being local market leaders, the target SHBs have renowned reputations amongst travelers as indicated by the locally well-accepted Ctrip rating (4.8 and 4.6 respectively).

\subsection{Case study background}

We contextualized the case in China primarily because China is one of the few countries worldwide that has so far successfully contained Covid-19 (Burki, 2020). The effective control of the virus replaced staged withdrawals of lockdowns in provincial regions across China with the implementation of "regular epidemic prevention and control" measures introduced by the government (Xinhua, 2020), and the social and economic normalcy was progressively restored and maintained from May 2020 onwards. It has, therefore, laid a robust and sustainable foundation on which the hospitality sector can gradually resume its business with assured confidences from customers, least impacted by disruptions that may be caused by repetitive waves of Covid-19 outbreaks seen elsewhere in other countries. As a result, the case in China provided us an ideal sample with which to examine the rebounding strategy through the pandemic, where the external environment is least violent and virulent. 
Following the purposive sampling strategy, two leading local SHBs, requesting anonymity, were selected as the focal case in Zhoushan City, one of the best-performing tourism cities in Zhejiang Province, China. The first SHB, "WTB", is amongst the most popular destinations with a $70 \%$ occupancy rate on average, and it is generally fully booked from May to October 2020 and during other holidays, with the price ranging from 600 to $900 \mathrm{RMB}$ per night. The second $\mathrm{SHB}$, "SCH", is popular with backpackers and young tourists and the yearly occupancy rate is approximately $60 \%$, with the daily price from 220 to $440 \mathrm{RMB}$. Due to the local government's containment measures as a result of the pandemic, both SHBs were required to suspend business during the outbreak. WTB gradually resumed operation from 1 April 2020 as the lockdown measures were phased out, while SCH remains closed as the "business outlook seems gloomy in the immediate future" (SCH owner). We summarized the occupancy rate and average price for both SHBs, and drew a straightforward comparison with the figures of the previous year in 2019 below (indicated from Figure 1 to Figure 4).

\section{$<$ Place Figure 1 to Figure 4 here>}

We chose both cases in Zhoushan for our research for the following reasons. Firstly, Zhoushan, located in eastern China and adjacent to Shanghai, is an island city of Zhejiang Province. Being one of the world's three largest fishery bases and the top tourism destinations in China, Zhoushan attracted 63.2 million tourists with a total revenue of 94.2 billion RMB in 2018 (Guizhou News Network, 2019). Given that most SHBs are not generally developed for business travelers, a recreational-oriented rather than commercial city such as Zhoushan is appropriate. Secondly, SHB is well developed in Zhoushan, according to the research of China Business Industry Research Institute (2018), where more than 1,320 are registered locally, ranking $8^{\text {th }}$ among all cities in China. SHB in Zhoushan is widely acclaimed for its high-quality tourism service, which ranks $1^{\text {st }}$ in mainland China. In this regard, Zhoushan has provided an ideal sample set, where the hospitality requirement (recreational tourism) and service standard are consistent and stable across all possible samples.

WTB and SCH are selected thereafter for this study because both share a wide range of similarities that make the cases comparable. They are located in neighboring suburbs, which are close in location. Being required to operate less than 15 rooms as per China's regulations, they are matching in scale (11 rooms vs. 7 rooms), decorated in similar styles (neo-Chinese), and are amongst the first batch of SHBs founded in Zhoushan (2017/2018). They, however, do differ in some other research-worthy aspects, making the study representative. WTB resumed its business after the lockdown, whereas SCH delayed the reopening, suggesting distinctive impacts from and various understandings toward the pandemic. More importantly, WTB is more digitally receptive than $\mathrm{SCH}$, making the samples exemplary regarding the focal aspect. The selection for this pair of cases is supported by Barret et al. (2011).

\subsection{Data analysis}

Table 1 summarizes the data collected and utilized in the study. In short, we collected data in several supplementary methods: semi-structured interviews with SHBs' owners and employees (interview plan is in Appendix), working documents from SHBs, and online reviews on leading local tourist platforms (Ctrip and Dianping). Additional data was collected via one-week on-site observations at WTB and an arranged visit to SCH. During the WTB on-site participation, the research team attended all meetings and had guided visits with the owner to its business fronts, including reception desk, cleaning, and dining service, while having the opportunity to interact with staff more casually. On the $\mathrm{SCH}$ side, the arranged visit covered a range of supplementary data collection activities, such as a direct view of the focal SHB situation and attendance at an $\mathrm{SCH}$ meeting. 
Aiming at the ambience surrounding SHBs during the pandemic, we utilized content analysis to analyze the data. The content analysis enables scholars to scour texts for replicable and valid references that surface from structural patterns while being linked to the context (Krippendorff, 2012). Content analysis is built upon the principle that a text, comprised of words, can be broken down into a number of content groups, each clustering around some keywords and conveying certain meanings that are analytically comparable for research endeavors (Stemler, 2015). As a result, the method can construct a well-focused and meaning-ridden context, in which a social-technical realm can be expressively established. In this research, we employed Nvivo 12 to analyze data in two coding rounds: the first round started with descriptive codes assigned to various data and generated main themes as the initial results through constant comparisons; the second round featured an iterative process, where aggregated and organized data were checked against the theory. Both together led to the identifications of the descriptively valid and theoretically reliable outcomes regarding the focal issue.

$$
\text { <Place Table } 1 \text { here> }
$$

\section{Findings}

Some illuminating findings are identified from the research, which help us formulate a better understanding towards the situation facing SHB in China throughout the pandemic. Based on the triangulated data, we clustered primarily three groups of factors that are exerting at different but related levels on SHB - operational level, managerial level, and transformational level (Table 2).

\section{<Place Table 2 here>}

\subsection{Operational Level}

The operational level mainly deals with four characteristics of SHB regarding the hospitality industry, which include scope, safety, security, and specialty. To be specific, scope speaks to the business range of SHB. In general, the scope of services provided by SHB in China is relatively narrow and linear, as both focal SHBs in the study only offer accommodation services; to their (owners') best knowledge, most of the other runners in Zhoushan more or less operate in a similar business range.

The SHB safety refers to hygienic and sanitary quality, where the differences between SHBs vary significantly, as indicated by owners and online reviews. While WTB sends all beddings to a specialized cleaning company and has hired dedicated cleaning staff since the reopening to wipe and clean all floors and in-room furniture frequently, $\mathrm{SCH}$ used its own washing machines and cleaning liquids once a week. Asked if $\mathrm{SCH}$ will introduce an enhanced cleaning standard once the business resumes, the owner cautions that "a careful decision will be made, taking cost and benefit into account". It is worth noting that since its reopening on 1 April, WTB booked the cleaning services online as "it is more organized, streamlined, and cost-efficient to a small business, and also becomes imperative to minimize unnecessary contact" (WTB partner).

Security means the general public order at SHB's premises and immediate surroundings. Despite the fact that the overall public security in China is well maintained, localized monitoring systems and inroom automatic alarms are not readily equipped at SHB, as illustrated in the cases. Aiming to provide a unique local experience for tourists, WTB and SCH are located near some off-street neighborhoods and close to primitive villages or beaches, suggesting that the surrounding areas are sparsely populated and inaccessible via public transport. Without enhanced measures, such as 24-hour security personnel patrolling, as most hotels do, security "remains a concern" among customers (online reviews). 
Specialty illustrates a discernible quality that SHB leverages as the key selling point to reach potential customers. Both SHBs treated the neo-Chinese decoration style and sea-view rooms as the selfbranding and marketing tactics, providing tourists with a similar attraction that becomes hardly perceptible for most customers. As a result, the rating of online distribution channels of SHB, such as Ctrip, becomes a primary indicator of its specialty and both SHBs (WTB and SCH owners) increasingly rely on the rating as the de facto selling point. WTB, however, has advised that it has set out a scheme to introduce a complementary local cuisine service and cultural outing service that can be pre-booked online in the forthcoming months via social media (for instance, Wechat and Weibo), and will use live broadcasts (for instance, Tiktok) as additional selling points.

\subsection{Managerial Level}

The managerial level relates to three SHB-focused capabilities of expertise, experience, and exchequer. Both factors of expertise and experience are concerned with the management team of SHB. According to the report (Analysis, 2017), 70\% of SHB operators are in their late 20 s or early 30 s and who do not possess specialized knowledge or relevant industry experience. This concurs with the cases where most employees, especially the two owners of SHB, are inexperienced in the industry sector. WTB's owner initiated the business out of his investment plan, while his $\mathrm{SCH}$ counterpart carried out SHB for his personal preference for more "flexible work with self-freedom" rather than a nine-to-five job.

Exchequer is another big issue facing SHB, which is regarding the financial capability of the organization. As the majority of SHBs are privately owned and independently operated (Liu et al., 2020), the largest spending is on property rental, initial decoration, and promotion cost; as a result, the cash flow, primarily depending on the income of rooms, is limited. In the case of an encounter with some unexpected risks, such as the pandemic, the financial pressure is mounting to the extent that SHB cannot willingly cope with it. SCH acknowledged that the exchequer situation is the major burden that is preventing it from reopening promptly.

\subsection{Transformational Level}

The transformational level describes the state of SHB in the context of digital innovation. Digitization refers to the move of SHB from being physical to being digital for a portion of, if not the entirety of, its process. Due to the introduction of digital innovation in the hospitality sector, especially the trend of SE and various sharing platforms, SHB digitizes the booking process in a revolutionary manner; in our case studies, both SHBs fully leverage online channels for room booking. The owner of SCH specified that the booking service is the only digitalized unit in its business process and "no others are currently undertaken online". In contrast, WTB is more responsive to digital innovation as, apart from booking, it endeavors to reach out to the other areas where digitalization is progressively utilized, such as online marketing, personalized services for returning customers, a state labelled as being en route to digitalization. Digitalization relates to the change of business processes through digital innovation. It helps businesses expand into new threads, and allows SHB to develop innovative products and/or services that were previously unavailable or extortionate, attracting a wider variety of customers.

\subsection{Summary}

We identified nine factors that are categorized into three levels - operational level, managerial level, and transformational level. They together provided a snapshot of how SHB in China is currently performing. Considering the context of the ongoing pandemic, we argue that SHB is externally challenged at the operational level as the scope is narrow in general, safety and security are insufficient, and specialty is limited. SHB is internally disadvantaged at the managerial level given the fact that the management team's expertise and experience are lacking and the exchequer is 
inadequate. Furthermore, SHB is essentially circumscribed at the transformational level since digitization has not yet permeated through SHB to achieve the digitalization where its business process is expected to be upgraded. To this end, regarding Research Question 1, the reason that SHB is particularly affected by the pandemic is the synthesis of three categorized factors exerting at operational, managerial, and transformational levels, as SHB is externally, internally, and essentially restricted.

\section{Conclusions and discussion}

\section{Conclusions}

By drawing on IT, we constructed relationships between factors and across three levels to build up the theoretical framework as a SHB rebound matrix, which is specified in Table 3.

\section{$<$ Place Table 3 here $>$}

IT posits that technology must be understood at the function dimension and the implementation dimension, so as to provide analysis from specific and general aspects. While the function dimension primarily talks about the useful properties of devices and systems, the implementation dimension concentrates on the natural and social contexts of the focal objects. The pair of digitation and digitalization exemplifies the two dimensions, as digitization is the change of functions to digital form and digitalization upholds the restructuring of processes in the business context strategically. We labelled the transformational level as the strategy the SHB is expected to be taking, and both operational and managerial levels as the resources the SHB is able to leverage.

For the time being, as indicated from the cases, SHB is partially digitized for internal and external resources, but digitalization is in its infancy. By adopting digitization at the managerial level (expertise, experience, and exchequer), SHB is able to develop the products (the rooms) from their own understanding regardless of the detrimental aspects, such as insufficient expertise, limited experience, and tight exchequer. On the one hand, as long as the products are visible online (i.e., SE platforms), the booking is supposed to be completed for SHB. On the other hand, in order to counterbalance the over-reliance on online channels, SHB should take diversified medium as the outstretched means to engage customers; for example, WTB is considering a promotion plan that will be primarily broadcast via TikTok for what the owner called "direct marketing and booking". In all, at Column I, digitization enables the management of SHB, making it feasible for most practitioners and accessible for customers (Donders et al., 2018).

When digitization is applied at the operational level (scope, safety, security, and specialty), SHB is expected to co-ordinate external resources in an efficient manner to better meet the enhanced hospitality requirements brought about by the pandemic. For instance, catering services are generally lacking in SHB and the pandemic has aggravated the concern over the quality and hygiene of food provision. Compared to traditional hotels, which employ dedicated teams for catering, for SHB in China, due to its business size and financial situation, a similar option is not readily on the table. However, a digitalized solution, such as online outsourcing, can be coordinated to enhance SHB's competitiveness while maintaining the desirable standards of operations. The aforementioned WTB scheme of cuisine and outing services serves as the latest example of how digitization can assist its operations. Column II, therefore, recommends and anticipates efficient coordination of external resources that has not been widely achieved amongst SHBs in China (Alshawaaf and Lee, 2020). 
As a step further, digitalization will witness a fundamental change in the landscape of SHB. If digitalization takes place internally as a result of three factors (expertise, experience, and exchequer), the current shortcomings identified can be further assuaged. After reopening, WTB initiated a campaign in an effort to provide tailored services to the customers based on the analysis of historical data, as the owner understood that the comparative advantage of WTB is to "correctly identify the potential targeted customers and strive to conveniently and economically reach them as precisely as possible". Generally, Column III advocates establishing a platform so that management, based on internal resources, can be promptly enhanced, such as cross-channel online marketing through data analytics (Autio, 2017).

Speaking from external resources, digitalization will push the data-driven business processes to an unprecedented front by integrating personalized services across all operational factors. For instance, SHB can be better combined with local cultural and social characteristics, fostering an immersive accommodation, which can effectively address the prevailing concerns over the homogenization issue facing SHBs in China. This can be achieved through the introduction of digitalized transformation, such as online check-in/out, unstaffed on-call service, etc. Column IV depicts an attainable target by utilizing digitalization in SHB business processes (Baiyere et al., 2020).

We hence suggest that SHB can rebound through the pandemic by further enhancing its digital journey progressively from digitization at its birth to digitalization in its prime. Regarding Research Question 2 , this transformation will witness a leap from product development to platform establishment internally and a stride from efficient coordination to effective integration externally. On a broader scale, the pair of digital activities foresee a meaningful utilization of digital technologies to transform the existing business model, thereby providing new revenue and renewed opportunities that move towards a digital business (Rijswijk, 2020). The transformation is particularly important and constructive for SHBs throughout the pandemic as the pair will effectively reduce the operation cost and bridge the industry gap, and efficiently display SHBs in the market across platforms and organize a renewal management strategy.

\section{Theoretical implications}

This paper explores the reasons behind SHBs in China being significantly affected by the pandemic and proposes the measures that SHBs can undertake in order to rebound through the crisis. It does so through a qualitative case study with two local appropriate and carefully selected SHBs in China by drawing on IT to develop a theoretical framework. Theoretically, the two-case study enabled us to identify a collection of factors at operational, managerial, and transformational levels, respectively, that explain how and why the setbacks brought on by the pandemic affected SHBs in China, confirming that SHB is internally, externally, and essentially restricted. Previous studies of SHB in China are largely limited and sporadic. Our research extended the scope by providing an initial effort in further understanding the influences of the pandemic on SHB from a digital perspective, which is generally downplayed and even overlooked.

Furthermore, through the adoption of IT, we developed a theoretical framework of SHB rebound matrix to render a set of measures that assist SHB in bouncing back after the crisis. SHB is recommended to utilize digitized and digitalized strategies, in line with the function and implementation levels advocated by IT, for both internal and external resources to realize the transformations from product development to platform establishment, and from efficient coordination to effective integration. This matrix is amongst the first theory-based endeavors to examine SHBs in a scholarly manner, and, more importantly, the timely theoretical examination into SHBs' strategy throughout the pandemic. It avoids atheoretical and descriptive rhetoric by holding an 
in-depth analysis at internal and external levels from essentially digitized and digitalized perspectives. The study thus highlights the pivotal role of the pair of digital activities (digitization and digitalization) in developing and sustaining a robust SHB development trajectory. As such, it contributed to the SHBrelated researches by contextualizing it in the context of a pandemic while also exemplifying it with two cases in China - one of the most successful Covid-19 control countries.

\section{Practical implications}

Practically, the research supports SHB practitioners on "survive, revive, and thrive" strategies after the crisis, and recommends SHB to further unleash the potential of digital business for a prompt transformation. With a continued favorable macro-environment that supports business resumption in China, the pair of digital activities (digitization and digitalization) can provide a reference guide for a feasible and workable roadmap that SHBs can reasonably and sensibly follow. To be specific, departing from the current product development on a digitized basis, SHB may better maneuver internal resources through digitalization to establish a platform, where cross-channel management can be achievable. This suggests that SHB should aggregate data from various channels across its business, and properly use the accumulative data to formulate insights that further lead to an omnichannel platform. In addition, SHB is currently short of efficient coordination in its external resources, which has disadvantaged SHB. As a result, SHB should continue to ramp up concerted efforts in a digitized manner for these essential hospitality services through the endeavors, such as digitized safety measures, digitized security provisions, and digitized selling points. SHB thereafter must step up its vision and mission via digitalization to effectively integrate all available sources. The research hence sheds light on a feasible and workable road map that SHB can follow to better cope with the crisis and take the challenges as opportunities for sustainable developments.

\section{Limitations and Future Research}

The research has two limitations. One concern is regarding the sample size. Despite the strenuous efforts in data collection, we caution that two cases may not be able to provide an exhaustive story regarding SHB in China, especially during and after the pandemic. From the data collection perspective, although both cases are leading local SHBs, this may have limited the size unnecessarily and thus the study was not able to render detailed accounts of every particular under the SHB context in China. It further gives rise to another concern surrounding the method of the case study. The case study was chosen in line with the data availability and richness given the timing and scope of this research, which may encounter the issue of generalization into wider populations. As such, this study encourages future research to administrate a large amount of data based on the current findings through more in-depth approaches, which can leverage both qualitative and quantitative methods, in the future.

\section{References}

Alshawaaf, N. and Lee, S.H. (2020), "Business model innovation through digitisation in social purpose organisations: a comparative analysis of Tate Modern and Pompidou Centre", Journal of Business Research.

Analysis. (2017), "Analysis of China's Online Homestay Reservation Market in 2017" (in Chinese).

Ankiewicz, P.J. (2019), "Andrew Feenberg: Implications of critical theory for technology education", In Reflections on Technology for Educational Practitioners, Brill Sense, pp.115-130

Autio, E. (2017), "Digitalisation, ecosystems, entrepreneurship and policy. Perspectives into topical issues is society and ways to support political decision making", Government's Analysis, Research and Assessment Activities Policy Brief, 20. 
Babbie, E. and Mouton, J., (2001), "Qualitative data analysis", The Practice of Social Research, South Africa Edition, pp.489-516.

Baiyere, A., Salmela, H. and Tapanainen, T. (2020), "Digital transformation and the new logics of business process management", European Journal of Information Systems, pp.1-22.

Barratt, M., Choi, T.Y., and Li, M. (2011), "Qualitative case studies in operations management: trends, research outcomes, and future research implications", Journal of Operations Management, 29(4), pp.329-342.

Barron, K., Kung, E. and Proserpio, D. (2018), "The sharing economy and housing affordability: evidence from Airbnb", available at: https://ssrn.com/abstract=3006832 (accessed 23 July 2020)

Baum, T. and Hai, N.T.T. (2020), "Hospitality, tourism, human rights and the impact of COVID-19", International Journal of Contemporary Hospitality Management, Vol. 32 No. 7, pp. 2397-2407.

Boelt, A. and Sorensen, E.K. (2017), "Digital Bildung in the Danish Higher Technical Examination Programme", In European Conference on e-Learning (pp. 65-69). Academic Conferences International Limited.

Bos, A.P. (2008), "Instrumentalization theory and reflexive design in animal husbandry", Social Epistemology, 22(1), pp.29-50.

Burki, T. (2020), "China's successful control of COVID-19", The Lancet Infectious Diseases, 20(11), pp.1240-1241.

Bygrave, W. (1989), “The entrepreneurship paradigm (I): a philosophical look at its research methodologies", Entrepreneurship Theory and Practice 14(1), pp.7-26.

Camilleri, J. and Neuhofer, B. (2017), Value co-creation and co-destruction in the Airbnb sharing economy. International Journal of Contemporary Hospitality Management.

CHA. (2020), "Report on the impacts and trend of Covid-19 on China's hospitality sector" (in Chinese), available at: https://www.meadin.com/vi/211604.html (accessed 23 July 2020)

China Business Industry Research Institute. (2018), "2018 China homestay industry market outlook research report", available at: https://www.askci.com/news/chanye/20180404/112702121001 2.shtml (accessed 23 July 2020)

China Government (2020), "China releases guideline on advancing work resumption amid epidemic control", english.www.gov.cn., available at: http://english.www.gov.cn/policies/latestreleases/202004/10/content WS5e8fd97cc6d0c201c2c c09b0.html (accessed 28 December 2020)

China Tourism Homestay Development Association. (2019), "2019 China homestay industry development research report", available at: https://tech.sina.cn/2020-03-23/detailiimxyqwa2697605.d.html?from=wap (accessed 23 July 2020)

Costa, L.S. (2020), "Contributions from the critical theory of technology to the analysis of innovation in health services", Interface-Comunicação, Saúde, Educação, 24, p.e190723.

Creswell, J.W. (2009), Research Design: Qualitative and Mixed Methods Approaches, London and Thousand Oaks: Sage Publications.

Crotty, M. (1998), The Foundations of Social Research, Sage Publications, London.

Donders, K., Enli, G., Raats, T. and Syvertsen, T. (2018), “Digitisation, internationalisation, and changing business models in local media markets: an analysis of commercial media's perceptions on challenges ahead", Journal of Media Business Studies, 15(2), pp.89-107.

Escobar, E. (2016), "The sharing economy: concepts and lessons for hospitality", HN, available at: https://www.hospitalitynet.org/opinion/4076818.html (accessed 23 July 2020)

Fang, B., Ye, Q. and Law, R. (2015), "Effect of sharing economy on tourism industry employment", Population, 1, pp.0-6321.

Feenberg, A. (2008), "Critical theory of technology: an overview", Information technology in librarianship: New critical approaches, pp.31-46.

Feng, X., and Han, W. (2020), "Analysis of knowledge map of domestic home stay industry development research (in Chinese)", Tourism Research, 12.2: pp.49-60. 
Forgacs, G., Dimanche, F. (2016), "Revenue challenges for hotels in the sharing economy: facing the Airbnb menace", Journal of Revenue Pricing Management, 15, 509-515 (2016).

Gerring, J. (2004), "What is a case study and what is it good for?", American Political Science Review, pp.341-354.

Guizhou News Network., (2019), "Zhoushan Zhejiang: More Than 60 Million Tourists a Year (in Chinese)", available at: http://www/chth.cn/lyms/18440.html (accessed 23 July 2020)

Guo, J., Ma, Y., Wang, C. and Qiu, T. eds. (2020), Annual Report on Homestay in China. Beijing, China: Social Sciences Academic Press.

Gupta, R. (2020), "Chinese hotel CEOs gear up for new normal, expect rebound by mid-Q2", available at: https://www.chinatravelnews.com/article/136743 (accessed 23 July 2020)

Guterres, A. (2020), "This is a time for science and solidarity", available at: https://www.un.org/en/un-coronavirus-communications-team/time-science-and-solidarity (accessed 23 July 2020)

Hospitality and Catering News. (2020), "Coronavirus: 80\% Of Chinese hotel rooms empty", Hospitality and Catering News, available at:

https://www.hospitalityandcateringnews.com/2020/02/coronavirus-80-chinese-hotel-roomsempty/(accessed 23 July 2020)

Jiang, J., Li, Y. (2014), "A review of research on homestay in tourism at home and abroad", Tourism Research (in Chinese), 006(004): pp.16-22

Jiang, Y. and Wen, J. (2020), "Effects of COVID-19 on hotel marketing and management: a perspective article", International Journal of Contemporary Hospitality Management, Vol. 32 No. 8, pp.2563-2573.

Jones, P. and Comfort, D. (2020), "The COVID-19 crisis and sustainability in the hospitality industry", International Journal of Contemporary Hospitality Management, Vol. 32 No. 10, pp.3037-3050.

Kamin, D. (2020), "My government-mandated quarantine at a five-star hotel", available at: https://www.cntraveler.com/story/my-government-mandated-quarantine-at-a-five-starhotel?verso=true (accessed 23 July 2020)

Knight, D.W., Xiong, L., Lan, W. and Gong, J. (2020), "Impact of COVID-19: research note on tourism and hospitality sectors in the epicenter of Wuhan and Hubei Province, China", International Journal of Contemporary Hospitality Management, Vol. 32 No. 12, pp.3705-3719.

Krippendorff, K. (2012), Content analysis: an introduction to its methodology (3rd ed.). Thousand Oaks, CA: Sage.

Lai, I.K.W. and Wong, J.W.C. (2020), "Comparing crisis management practices in the hotel industry between initial and pandemic stages of COVID-19", International Journal of Contemporary Hospitality Management, Vol. 32 No. 10, pp. 3135-3156.

Lee, R. M. (2004), Recording Technologies and the Interview in Sociology, 1920-2000. Sociology, 38(5): 869-899.

Li, Y.Q., Yu, W.H. and Bai, Y.F. (2017), "Comparative research on B\&B of Beijing and Taipei based on ratings on the Airbnb website", Chinese Journal of Management, 14(1), pp.122-128.

Liu, C. W.; Cheng, J.-S. (2018), "Exploring driving forces of innovation in the MSEs: the case of the sustainable B\&B tourism industry", Sustainability 10, 3983

Liu, W., Ji, R., Nian, C.P., Ryu, K. (2020), "Identifying the types and impact of service provider's responses to online negative reviews in the sharing economy: evidence from B\&B in China", Sustainability 2020, 12, 2285.

Luo, Y. (2017), "The standardization and characteristic of homestay design and development (in Chinese)", Economic and Trade Practice, pp.52-54

Lyu, J., Li, M., Law, R. (2019), "Experiencing P2P accommodations: anecdotes from Chinese customers", International Journal of Hospitality Management, 77, pp.323-332.

Myers, M.D. (2019), Qualitative research in business and management. Sage Publications Limited.

Paul, J. (1996), "Between-method triangulation in organizational diagnosis", International Journal of Organizational Analysis, Vol. 4 No. 2, pp.135-53. 
Price, S., Jewitt, C. and Brown, B. eds. (2013), The Sage handbook of digital technology research. London: Sage.

Radzi, S., Sumarjan, N., Chik, C., Zahari, M., Mohi, Z., Bakhtiar, M. and Anuar, F. (2014), "Theory and Practice in Hospitality and Tourism Research", Penang Malaysia: CRC Press, p.241

Rein, R. (2017), "The sharing economy: opportunities for hoteliers", EHL Insights, available at: https://hospitalityinsights.ehl.edu/sharing-economy-opportunities-hotel-industry (accessed 23 July 2020)

Ridder, H.G., (2017), "The theory contribution of case study research designs", Business Research, 10(2), pp.281-305.

Rijswijk, K. (2020), Digital Transformation: Ongoing digitalisation and digitalisation processes. Desira, Wagenigen University and Research.

Robinson, K.M. (2001), "Unsolicited narratives from the Internet: a rich source of qualitative data", Qualitative Health Research, 11(5), pp.706-714.

Sigala, M. (2018), "Implementing social customer relationship management: a process framework and implications in tourism and hospitality", International Journal of Contemporary Hospitality Management, Vol. 30 No. 7, pp.2698-2726.

Smith, K.G., Gannon, M.J. and Sapienza, H.J. (1989), "Selecting methodologies for entrepreneurial research: trade-offs and guidelines", Entrepreneurship theory and practice, 14(1), pp.39-50.

Souza, L.E.P.F.D. (2016), "Health, development and innovation: a contribution of the critical theory of technology to the discussion", Cadernos de saude publica, 32, p.e00029615.

Stake, R. E. (2005), “Qualitative case studies”, In N. K. Denzin and Y. S. Lincoln (Eds.), Handbook of qualitative research, 3rd ed., pp. 443-466, Thousand Oaks, CA: Sage

Stemler, S.E. (2015), "Content analysis", Emerging Trends in the Social and Behavioral Sciences, John Wiley \& Sons, Hoboken, N.J., pp.1-14.

Sun, H. (2019), "Discussion on the types of residents and marketing strategies of guesthouses in second-tier cities (in Chinese)", Enterprise Forum, 8.

Sun, Y., Hu, M., and Xu X. (2016), "On the synergetic development strategy of homestay economy and regional culture (in Chinese)", Journal of Zhejiang University of Technology (Social Science), 15.2 .

Suo, Y. (2017), "An analysis of young Chinese customer preferences for B\&B services", Tampere University Thesis

Wang, J., Ceng, S., Li, J., Nong, X., Li, C., Liang, R. (2019), “Analysis on the existing problems and countermeasures of resident homestay management in Longji terrace scenic spot in Guilin (in Chinese)", The Operation and Management.

Williams, C.C. and Horodnic, I.A. (2017), "Regulating the sharing economy to prevent the growth of the informal sector in the hospitality industry", International Journal of Contemporary Hospitality Management, Vol. 29 No. 9, pp.2261-2278

Xiao, Y., Tang, J., and Feng, H. (2019), "Chengdu rural guesthouse promotion against the background of rural revitalization (in Chinese)", Journal of Chengdu University (Social Sciences), 186(6).

Xinhua (2020), "China introduces guidelines on regular COVID-19 epidemic containment", Xinhua.net, available at: http://www.xinhuanet.com/english/2020-05/08/c 139040522.htm (accessed 28 December 2020)

Xu, K. (2020), "B\&Bs in Zhejiang Province, China: developments and issues", 5th International Conference on Social Science and Management, Hangzhou, China, pp.507-511.

Yin, R. K. (2009), Case study research: Design and methods (4th ed), Thousand Oaks, CA: Sage

Yin, R.K. (2013), "Validity and generalization in future case study evaluations", Evaluation, 19(3), pp.321-332.

Zainal, Z. (2007), "Case study as a research method", Jurnal Kemanusiaan, 5(1).

Zhai, J. (2016), "Research on the design of rural boutique B\&B in the context of rural construction (in Chinese)", Master Thesis of Zhejiang University. 
Zhang, C. (2019), "Research on improvement route for SHB in Huangshan based on value theory (in Chinese)", Master Thesis of East China University of Political Science and Law

Zhang, C., Wang, M. (2017), "The development status and strategy of homestay in China (in Chinese)", The Age of Wisdom and Wealth, 2017 (1)

Zhang, X., and Hu, M. (2016), "Analysis on the position, present situation and development way of guesthouse industry under the background of the transformation and upgrading of rural tourism: a case study of the guesthouse industry in Hangzhou (in Chinese)", Value Engineering 23.

Zhu, C. (2014), "Study on the countermeasures of rural tourism development on homestay facility in Yongjia county Zhejiang (in Chinese)", Master Thesis of Jilin University. 


\section{Semi-Structured Interview Plan}

\section{Basics}

Obtain interviewees' basic information, such as age range, education background, professional background, industry experience, and digital experience, in de-identified manner

\section{Opening}

1. SHB specifications: establishment date, the number of available rooms, and the number of employees.

2. SHB business: business type (all-in-one self-operating/partial outsourcing), business segmentation, and overall business orientation and strategy.

\section{Digital innovation and Pandemic}

1. Digital innovation

1.1 Penetration of digital innovation into SHB, such as dedicated web page, online reservation, online marketing

1.2 Platforms of online activities - which, what percentage, how and why

1.3 Digital innovation's role in SHB before the pandemic

2. Pandemic impact
2.1 Direct impact
2.2 Indirect impact
2.3 Impact comparison between SHB and traditional hotel

3. Post-lockdown influence

3.1 Measures being taken after lockdown

3.2 Further digital innovation being considered

(1) Yes: which innovation/s? Why do you choose it? How are you going to leverage it?

(2) No: why do you not choose any?

4. SHB outlook for digital innovation through the pandemic
4.1 Data collection plan

4.2 Digital transformation plan

4.3 Digital investment plan

\section{Conclusion}

1. Do you have any thoughts during the interview?

2. Do you have any questions? 


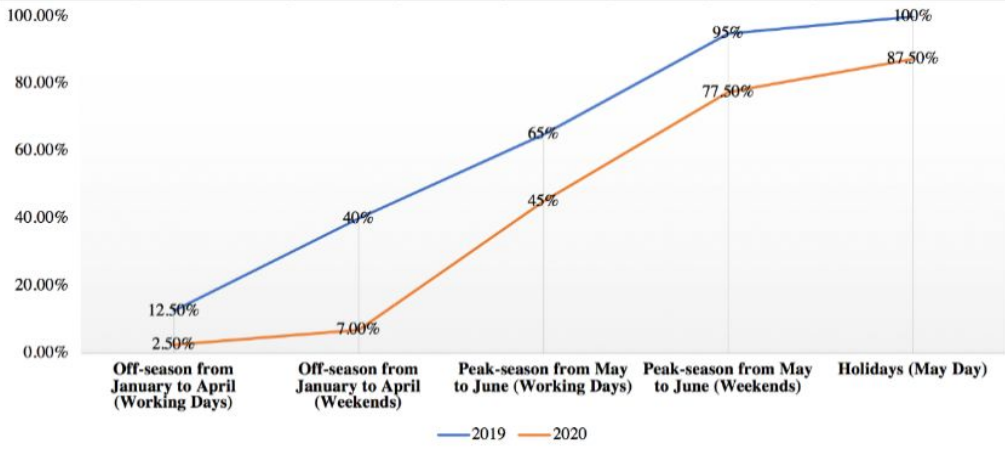

Figure 1: WTB Occupancy Rate

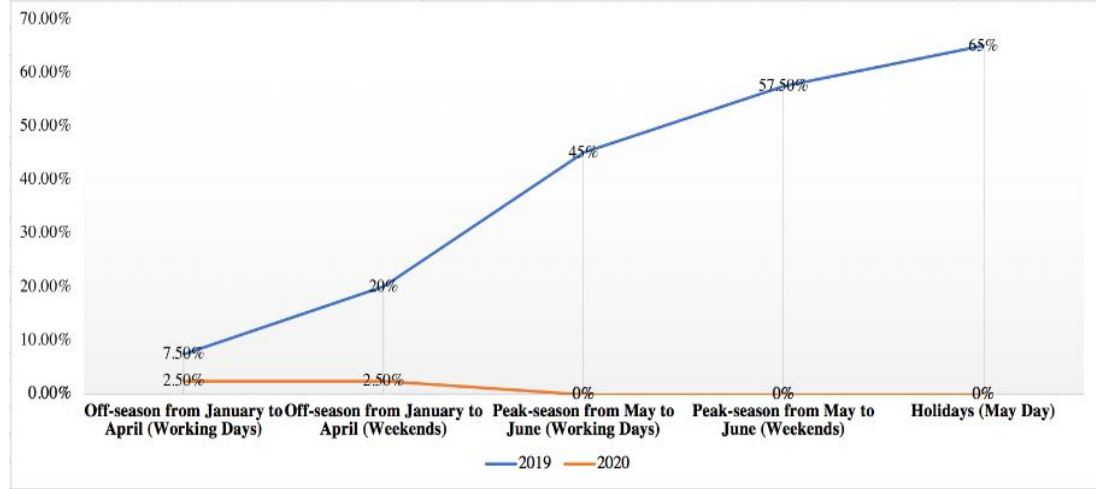

Figure 2: SCH Occupancy Rate

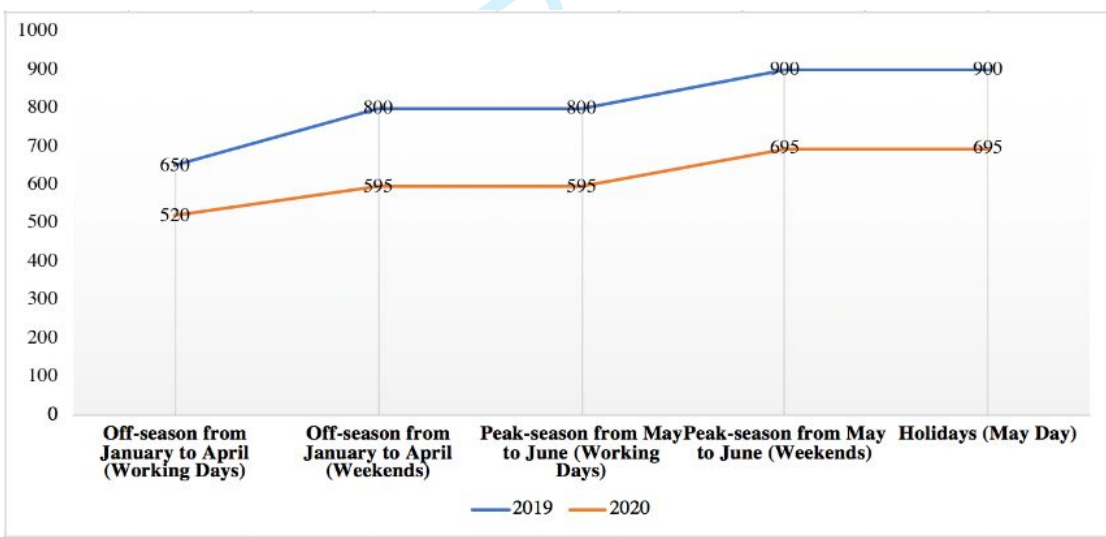

Figure 3: WTB Average Price

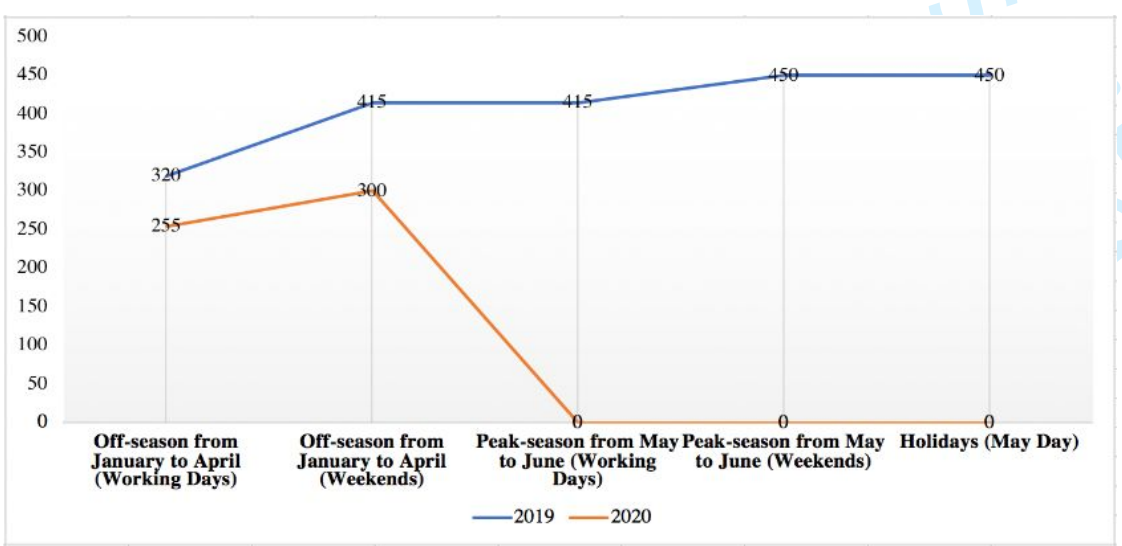

Figure 4: SCH Average Price 
Table 1: Source of case study data

\begin{tabular}{|c|c|c|}
\hline Data Type & Specifications & Details \\
\hline & WTB owner & Once for 1 hour \\
\hline \multirow{5}{*}{ Interview } & WTB partner & Thrice for 6 hours \\
\hline & $\begin{array}{c}\text { WTB employees } \\
\text { (Two Receptionists, one cleaning staff, and } \\
\text { three dining staff) }\end{array}$ & Once for each and 4.5 hours \\
\hline & $\mathrm{SCH}$ owner & Twice for 2 hours (online) \\
\hline & SCH partner & Twice for 3 hours \\
\hline & $\begin{array}{l}\mathrm{SCH} \text { employee } \\
\text { (One receptionist) }\end{array}$ & Once for 1 hour (online) \\
\hline \multirow{7}{*}{$\begin{array}{l}\text { Working } \\
\text { Document }\end{array}$} & WTB monthly working reports & 8 reports \\
\hline & Minutes of selected WTB meetings & 12 documents \\
\hline & WTB daily memos & Jan - Aug, 2020 \\
\hline & WTB monthly/quarterly business reports & $\begin{array}{l}8 \text { monthly reports } \\
2 \text { quarterly reports }\end{array}$ \\
\hline & SCH working reports & 3 reports \\
\hline & Minutes of selected SCH meetings & 4 documents \\
\hline & $\mathrm{SCH}$ monthly/quarterly business reports & $\begin{array}{l}4 \text { monthly reports } \\
1 \text { quarterly report }\end{array}$ \\
\hline \multirow{2}{*}{ Online Review } & \multirow{2}{*}{ Reviews posted before/after lockdown } & Ctrip (182 reviews) \\
\hline & & Dianping (30 reviews) \\
\hline \multirow{2}{*}{ Alternative Data } & WTB on-site observations & One-week in Aug, 2020 \\
\hline & An arranged visit to $\mathrm{SCH}$ & Two-hour visit in Aug, 2020 \\
\hline
\end{tabular}


Table 2: Affecting Factors across Three Levels

\begin{tabular}{|c|c|c|c|}
\hline Axis & Level & Factor & Brief Note \\
\hline \multirow{7}{*}{ Resource } & \multirow{4}{*}{$\begin{array}{l}\text { Operational } \\
\text { Level (4S) }\end{array}$} & Scope & The business range that SHB is operating within \\
\hline & & Safety & The hygienic and sanitary quality of SHB \\
\hline & & Security & The public order at SHB's premise and immediate surrounding \\
\hline & & Specialty & The key selling point/s of SHB \\
\hline & \multirow{3}{*}{$\begin{array}{l}\text { Managerial } \\
\text { Level (3E) }\end{array}$} & Expertise & Management team's professional capability in the sector \\
\hline & & Experience & Management team's prior engagement capability in the sector \\
\hline & & Exchequer & SHB's financial capability \\
\hline \multirow{2}{*}{ Strategy } & \multirow{2}{*}{$\begin{array}{c}\text { Transformational } \\
\text { Level (2D) }\end{array}$} & Digitization & SHB's move from being physical to being digital \\
\hline & & Digitalization & SHB's change of business process through digital innovation \\
\hline
\end{tabular}

Table 3 SHB Rebound Matrix

\begin{tabular}{|c|c|c|c|}
\hline \multirow{2}{*}{\multicolumn{2}{|c|}{ SHB Rebound Matrix }} & \multicolumn{2}{|c|}{ SHB Strategy } \\
\hline & & \multicolumn{2}{|c|}{ Essential (2D) } \\
\hline & & Digitization & Digitalization \\
\hline \multirow{3}{*}{$\begin{array}{c}\text { SHB } \\
\text { Resources }\end{array}$} & $\begin{array}{l}\text { Internal } \\
(3 E)\end{array}$ & $\begin{array}{c}\text { Column I } \\
\text { Product Development } \\
\text { SHB focuses on developing rooms } \\
\text { based on own understanding througr } \\
\text { digitization process, e.g., online } \\
\text { booking }\end{array}$ & $\begin{array}{c}\text { Column III } \\
\text { Platform Establishment } \\
\text { SHB aims to establish platform based on } \\
\text { data-enabled insights through } \\
\text { digitalization transformation, e.g., } \\
\text { online cross-channel marketing }\end{array}$ \\
\hline & & $\begin{array}{c}\text { Column II } \\
\text { Efficient Coordination }\end{array}$ & $\begin{array}{c}\text { Column IV } \\
\text { Effective Integration }\end{array}$ \\
\hline & $\begin{array}{c}\text { External } \\
(4 S)\end{array}$ & $\begin{array}{c}\text { SHB focuses on coordinating } \\
\text { necessary services based on necessar } \\
\text { hospitality requirements through } \\
\text { digitization process, e.g., online } \\
\text { outsourcing }\end{array}$ & $\begin{array}{l}\text { SHB aims to integrate personalized } \\
\text { services based on data-facilitated } \\
\text { observations through digitalization } \\
\text { transformation, e.g., online check- } \\
\text { in/out }\end{array}$ \\
\hline
\end{tabular}

